
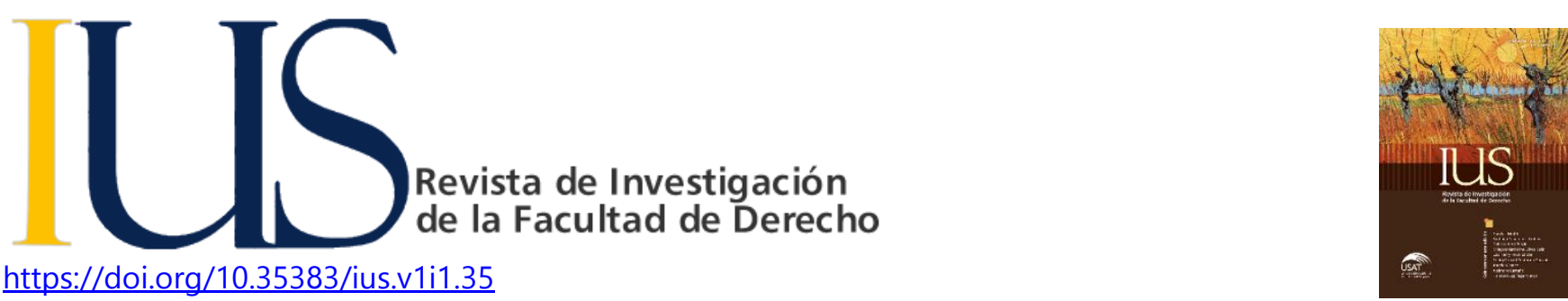

\title{
RELACIONES ENTRE EL ESTADO Y LAS CONFESIONES RELIGIOSAS EN ESPAÑA. APUNTES HISTÓRICOS Y REGULACIÓN ACTUAL A LA LUZ DE LA JURISPRUDENCIA DEL TRIBUNAL EUROPEO DE DERECHOS HUMANOS \\ Santiago Cañamares Arribas ${ }^{1}$
}

\begin{tabular}{|c|c|}
\hline INFORMACIÓN DEL ARTÍCULO & RESUMEN \\
\hline $\begin{array}{l}\text { Historia del artículo: } \\
\text { Recibido el } 1 \text { de octubre de } 2018 \\
\text { Aceptado el } 19 \text { de marzo de } 2019\end{array}$ & \multirow{2}{*}{$\begin{array}{l}\text { Hasta la entrada en vigor de la Constitución, el modelo constitucional } \\
\text { de relaciones Iglesia-Estado se caracterizó, salvo algunas breves } \\
\text { excepciones, por la confesionalidad católica. Bajo el actual régimen } \\
\text { constitucional se ha instaurado un régimen de laicidad positiva que } \\
\text { viene enmarcado por el principio de cooperación entre el Estado y las } \\
\text { confesiones y que sirve, a su vez, como garantía de la libertad religiosa. }\end{array}$} \\
\hline \multirow{3}{*}{$\begin{array}{l}\text { Palabras clave: } \\
\text { Neutralidad religiosa del Estado } \\
\text { Libertad religiosa } \\
\text { Derecho español } \\
\text { Cooperación Estado-confesiones } \\
\text { religiosas }\end{array}$} & \\
\hline & $\begin{array}{l}\text { Relations between the state and religious confessions in Spain. } \\
\text { Historical notes and current regulation in the light of the } \\
\text { jurisprudence of the European Court of Human Rights }\end{array}$ \\
\hline & ABSTRACT \\
\hline $\begin{array}{l}\text { Keywords: } \\
\text { State's religious neutrality Keywords2 } \\
\text { free exercise of religion } \\
\text { Spanish Law } \\
\text { State-religions cooperation }\end{array}$ & $\begin{array}{l}\text { Before the current constitutional regime, the Church-State relations } \\
\text { system was characterized by Catholic confessionalism. The approval of } \\
\text { the Spanish Constitution brought a new model of Church-State } \\
\text { relations that has been defined as positive secularism, framed by the } \\
\text { principle of cooperation between the State and the religious } \\
\text { denominations which serves as a guarantee of religious freedom. }\end{array}$ \\
\hline
\end{tabular}

\section{CONSIDERACIONES HISTÓRICAS}

Desde los inicios del constitucionalismo español, el modelo de relación entre el Estado y el fenómeno religioso se caracterizó, salvo puntuales excepciones, por la confesionalidad católica del Estado, que quedó definitivamente superada con la Constitución de 1978.

De entrada, en España, al contrario de lo que ocurrió en otros países de nuestro entorno, la aparición del Estado liberal no tuvo como efecto la instauración de un régimen de separación entre Iglesia y Estado. De hecho, la Constitución de Cádiz (1812), declaró en su artículo 12 que "La religión de la Nación española es y será perpetuamente la católica, apostólica, romana, única verdadera. La Nación la protege con Leyes sabias y justas y prohíbe el ejercicio de cualquier otra".

\footnotetext{
1 Doctor en Derecho. Departamento de Derecho Eclesiástico del Estado. Universidad Complutense de Madrid. sca@der.ucm.es
} 
La primera excepción a esta tendencia se encuentra en la Constitución de 1869 , donde no se contenía ninguna alusión expresa a la confesionalidad del Estado. No obstante, su artículo 21 seguiría afirmando "la obligación del Estado de mantener el culto y los ministros de la religión católica". Al mismo tiempo se garantizaba la libertad religiosa de españoles y extranjeros "sin más limitaciones que las reglas universales de la moral y del derecho".

Pocos años después, la Constitución de 1876 volvería a proclamar la confesionalidad católica en su art. 11 donde se reconocía que "La religión católica, apostólica, romana, es la del Estado. La Nación se obliga a mantener el culto y sus ministros." Curiosamente, aunque se disponía que nadie será molestado por sus opiniones religiosas ni por el ejercicio de su respectivo culto, salvo el respeto debido a la moral cristiana, no se permitían otras ceremonias ni manifestaciones públicas que las de la religión del Estado.

Este modelo confesional se mantendrá hasta la II República española, cuya Constitución de 1931 proclamó en su art. 3 que "el Estado español no tiene religión oficial". La libertad religiosa fue objeto de reconocimiento dispar pues, por una parte, quedaba suficientemente garantizada a nivel individual en su art. 27, mientras que cabía apreciar una actitud de hostilidad, inconciliable con la laicidad, frente a su dimensión colectiva, ya que su art. 26 dispuso la disolución de aquellas órdenes religiosas que impusieran un voto de obediencia a autoridad distinta de la del Estado (Compañía de Jesús), y a las demás, se les prohibió ejercer la industria, el comercio, la enseñanza, y se les declaró incapaces para adquirir más bienes que los dedicados al cumplimiento directo de sus fines. Con la Dictadura franquista (1939-1975) se volvió a la confesionalidad católica. De un modo contundente, la Ley de Principios del Movimiento Nacional (1958) declaró que la legislación nacional se adaptaría a la doctrina de la "Santa Iglesia católica, apostólica y romana, única y verdadera y

2 Por todas, Sentencia TC 24/1982, de 13 de mayo, fundamento jurídico 1. fe inseparable de la conciencia nacional". Quizá el ejemplo más claro de este paralelismo se encuentra en la aprobación en 1967 de la Ley de Libertad Religiosa, donde se contenía un reconocimiento formal de esta libertad, como consecuencia del reconocimiento de la libertad religiosa como derecho humano en la Declaración Dignitatis Humanae de 1965 (Blanco, 1999).

La vigente Constitución (1978) proclama en su artículo 16 el derecho de libertad religiosa de individuos y comunidades sin más limitación en sus manifestaciones exteriores que la necesaria para el mantenimiento del orden público protegido por la Ley. Al mismo tiempo, su apartado tercero proclama tanto la aconfesionalidad del Estado bajo la lacónica expresión de que "ninguna confesión tendrá carácter estatal" como el principio de cooperación entre el Estado y las confesiones religiosas, afirmando que "los poderes públicos tendrán en cuenta las creencias religiosas de la sociedad española y mantendrán las consiguientes relaciones de cooperación con la Iglesia católica y las demás confesiones religiosas".

Permítanme que me refiera ahora, separadamente, a cada uno de estos aspectos.

\section{LA LEY ORGÁNICA DE LIBERTAD RELIGIOSA}

Sobre el derecho de libertad religiosa, el Tribunal Constitucional ha afirmado que, en su dimensión interna, "garantiza la existencia de un claustro íntimo de creencias y, por tanto, un espacio de autodeterminación intelectual ante el fenómeno religioso, vinculado a la propia personalidad y dignidad individual", y asimismo, "esta libertad... incluye también una dimensión externa de "agere licere" que faculta a los ciudadanos para actuar con arreglo a sus propias convicciones y mantenerlas frente a terceros". Más en concreto, la dimensión externa de la libertad religiosa se traduce "en la posibilidad de ejercicio, inmune a toda coacción de los poderes públicos, de aquellas actividades que constituyen manifestaciones o expresiones del fenómeno religioso"2

Coincide con la doctrina sentada por el Tribunal Europeo de Derechos Humanos que distinguiría dentro de la libertad religiosa entre el "forum internum" que tendría un carácter 
El contenido del artículo 16 de la Constitución ha sido desarrollado por la Ley Orgánica 5/1980, de Libertad Religiosa (Boletín Oficial del Estado, 1980). Este texto ha gozado de un indiscutible reconocimiento jurídico en el ámbito nacional e internacional. Su reconocimiento en el ámbito nacional responde a dos fundamentales razones. En primer lugar, al amplio consenso que llevó a su aprobación, que contó con 294 votos a favor cinco abstenciones y ningún voto en contra (Ciaurriz, 1984) y, en segundo lugar, al acierto del legislador de elaborar una ley abierta que permite su adaptación a las distintas circunstancias que el ejercicio de la libertad religiosa ha venido planteando desde su aprobación hasta la actualidad. En lo que se refiere al reconocimiento internacional, es fácil constatar cómo el vigente texto ha tenido una influencia directa sobre los modelos de relación entre el estado y las confesiones religiosas en Latinoamérica y en algunos países europeos (González, 2013; Cole Durham, 2006).

A la hora de valorar la oportunidad de esta norma, creo que resulta prudente dirigir la mirada hacia los modelos y las experiencias de otros estados de nuestro entorno. En el ámbito europeo, el modelo portugués -tributario en buena medida del español- se caracteriza por una legislación pormenorizada del libre ejercicio de la religión, donde también se contempla la cooperación estatal con las confesiones religiosas por vía de Acuerdo, si bien, con un margen de actuación reducido dada la regulación general contenida en la Ley. ${ }^{3}$

El modelo portugués contrasta con el modelo italiano, caracterizado por la ausencia de una

absoluto, en tanto se identifica con la libertad de creer o no creer y de cambiar de religión, y el "forum externum" que resultaría esencialmente limitable en tanto viene referido a la manifestación externa de las convicciones religiosas. Sobre esta doctrina, Murdoch (2012)

${ }_{3}^{3}$ Lei 16/2001, da Liberdade Religiosa, de 22 de Junho.

Sobre el contenido de esta norma García (2013), Llamazares (2002).

${ }^{4}$ Legge 24 giugno 1929, n. 1 159, Disposizioni sull'esercizio dei culti ammessi nello Stato e sul matrimonio celebrato davanti ai ministri dei culti medesimi. legislación de desarrollo del derecho de libertad religiosa, a pesar de los numerosos intentos de aprobación que se han sucedido desde los años 90 hasta la actualidad. Comoquiera que resulta necesario un sustrato normativo que permita articular el modelo paccionado de relaciones iglesia-estado previsto en la Constitución italiana, se ha mantenido la vigencia de la ley de cultos admitidos de 1929,4 que a pesar de haber sido aprobada en un contexto político y legislativo enteramente diferente al que alumbró la Constitución de 1947 sigue operando como marco regulatorio de la posición de las confesiones minoritarias en Italia, en tanto en cuanto no hayan firmado un acuerdo (intesa) con el Estado (GarcíaPardo, 1999).

A la vista de estos modelos, debemos plantearnos hasta qué punto resulta necesario en el ordenamiento jurídico español la existencia de una ley de desarrollo de la libertad religiosa, sobre todo, teniendo en cuenta, como ha reseñado nuestro Tribunal Constitucional en innumerables ocasiones, que los derechos fundamentales son directamente aplicables, sin que sea necesario para su ejercicio su previo desarrollo legislativo ${ }^{5}$. Sin duda, en lo que se refiere al desarrollo de la dimensión individual de la libertad religiosa el contenido de la Ley Orgánica puede considerarse más contingente ya que las condiciones de su ejercicio vienen marcadas por el juego conjunto de los artículos 16 y 10 de la Constitución que remiten a los textos internacionales de derechos humanos para precisar su contenido y límites, señaladamente los textos de la Organización de las Naciones Unidas ${ }^{6}$ y el Convenio Europeo de Derechos ${ }^{7}$.

5 Sentencia TC 53/1985, de 11 de abril, fundamento jurídico 14.

${ }^{6}$ Art. 18 de la Declaración Universal de Derechos Humanos (1948); Art. 18 del Pacto Internacional de Derechos Civiles y Políticos (1966) y, en general, la Declaración sobre Eliminación de todas las formas de discriminación basadas en la religión o en las convicciones (1981)

7 El derecho de libertad religiosa aparece recogido en el Art. 9 del Convenio. Un estudio sobre los límites al ejercicio de este derecho en el marco de la jurisprudencia del Tribunal Europeo de Derechos Humanos puede verse en Martínez (2003). 
En cambio, su aportación más trascendental se proyecta sobre las confesiones religiosas, ya que define su posición jurídica en nuestro Derecho, dotándolas de una personalidad jurídica específica frente a las propias del derecho común asociaciones y fundaciones- que se adquiere mediante su inscripción en el Registro de Entidades Religiosas, previsto en el artículo 5 de la citada Ley Orgánica8.

Entre los rasgos definitorios de esta personalidad se encuentra la plena autonomía doctrinal y organizativa frente al Estado y la posibilidad de firmar acuerdos de cooperación por aquellas confesiones que han obtenido el reconocimiento del notorio arraigo en España. ${ }^{9}$ Este diferente tratamiento jurídico viene justificado porque, como declaró el Tribunal Constitucional en su Sentencia 46/2001, de 15 de febrero, la propia formulación constitucional de la libertad religiosa permite afirmar que las confesiones no se identifican necesariamente con las asociaciones a que se refiere el art. 22 de la Constitución. ${ }^{10}$

Conviene aclarar, en este momento, que cuando un grupo goza de personalidad jurídica a través de alguna de las modalidades del derecho común, la denegación de la inscripción de una entidad religiosa en el Registro de Entidades Religiosas no entraña necesariamente una vulneración de su derecho de libertad religiosa colectiva, ${ }^{11}$ salvo que se trate de una decisión injustificada, en cuyo caso se traduciría en un obstáculo que menoscaba el ejercicio en plenitud del derecho fundamental de libertad religiosa del que son titulares los sujetos colectivos, ya sea en orden a que se les reconozca

\footnotetext{
8 Decreto 594/2015 (BOE de 1 de agosto de 2015). Sobre el contenido de esta norma reglamentaria puede verse Mantecón (2015)

${ }^{9}$ El artículo 7.1 de la Ley Orgánica de Libertad religiosa dispone lo siguiente: "El Estado, teniendo en cuenta las creencias religiosas existentes en la sociedad española, establecerá, en su caso, acuerdos o convenios de cooperación con las Iglesias, Confesiones y Comunidades religiosas inscritas en el Registro que por su ámbito y número de creyentes hayan alcanzado notorio arraigo en España. En todo caso, estos acuerdos se aprobarán por ley de las Cortes Generales."

10 Fundamento jurídico quinto.

1 Doctrina del Tribunal Europeo de Derechos Humanos, en la sentencia TEDH Ejército de Salvación (Delegación de Moscú) v.
}

formalmente una organización y régimen normativo propios, ya en lo concerniente a las manifestaciones externas en que se proyectan sus convicciones o creencias religiosas. 12

En este punto, conviene recordar la doctrina del Tribunal Europeo de Derechos Humanos según la cual la negativa de las autoridades de un Estado a reconocer personalidad jurídica -cualesquiera que sean sus rasgos- a una confesión religiosa entraña una vulneración de la libertad religiosa y del derecho de asociación reconocidos, respectivamente, en los artículos 9 y 11 del Convenio, en tanto de la falta de inscripción se deriva la imposibilidad de ejercer libremente las actividades propias del grupo religioso. ${ }^{13}$ En todo caso, el juego conjunto de estos derechos presenta un alcance mayor ya que protege la autonomía de la comunidad religiosa frente a cualquier injerencia arbitraria del Estado. Como señaló el Tribunal en Hassan y Chauch v. Bulgaria (2000) ${ }^{14}$, si la organización de la vida de la comunidad no estuviera protegida todos los demás aspectos de la libertad de religión del individuo estarían debilitados.

\section{CONSIDERACIONES ACERCA DE LA LAICIDAD DEL ESTADO}

En lo que se refiere a la aconfesionalidad del Estado, tanto la doctrina como la jurisprudencia constitucional han tratado de ir perfilando progresivamente el contenido de este principio. La bibliografía jurídica es muy abundante y sería excesivamente tedioso dejar constancia en estas páginas de todas las aportaciones. ${ }^{15}$ Más

Rusia, de 5 de octubre de 2006; también Sentencia TEDH Iglesia metropolitana de Besarabia y otros v. Moldavia, de 13 de diciembre de 2001.

12 Sentencia TC 46/2001, de 15 de febrero, fundamento jurídico 9

13 Sentencia I.M.B. ap. 129-130

14 Sentencia TEDH Hassan y Chauch v. Bulgaria, de 26 de octubre de 2000.

${ }^{15}$ A título ilustrativo de la muy abundante bibliografía sobre esta cuestión, cabe citar: Palomino, R. (2014); Ollero, A. (2005); Navarro-Valls, R. (2003); Viladrich, P.J., Ferrer, J. (2007); López, M. (1996); Llamazares, D. (1999); Roca, M. (2005); Suárez, G. (2006). 
abarcable resulta, en cambio, extractar la doctrina sentada sobre su contenido y consecuencias por el máximo intérprete de la Constitución.

Creo que de la jurisprudencia del Tribunal Constitucional cabe deducir dos grandes ideas. De una parte, que su razón de ser está en propiciar el ejercicio, en las mismas condiciones, del derecho de libertad religiosa por parte de los individuos y los grupos. Así, lo ha puesto de manifiesto, en diversas ocasiones, al señalar que la laicidad constituye una garantía de la libertad religiosa de todos. ${ }^{16} \mathrm{Y}$, de otra parte, que debe ser interpretada en clave positiva. ${ }^{17}$ No en vano, el artículo 9.2 de la Constitución ordena a los poderes públicos llevar a cabo actividades para garantizar que la libertad y la igualdad -también religiosas- de los individuos y grupos sean reales y efectivas. De ahí se deduce -como puso de manifiesto nuestro Tribunal Constitucional- 18 que la posición del Estado ante el fenómeno religioso no puede verse satisfecha con una actitud meramente abstencionista.

Es interesante destacar, en este punto, la sentencia $154 / 2002$, de 18 de julio, del Tribunal Constitucional, donde sostiene que la laicidad comporta la doble exigencia de la neutralidad de los poderes públicos, ínsita en la aconfesionalidad del Estado, y de la cooperación entre Iglesia y Estado. ${ }^{19}$

En efecto, nuestra Constitución exige de los poderes públicos la toma en consideración de las creencias religiosas de la sociedad para establecer las consiguientes relaciones de cooperación con las confesiones religiosas. El principio de cooperación constituye, sin duda, un elemento esencial para la adecuada comprensión de la laicidad en Derecho español que supera una concepción reduccionista en términos de estricta separación entre el Estado y las confesiones.

\footnotetext{
16 Sentencia TC 340/1993, de 16 de noviembre, fundamento jurídico. 4 En similares términos se expresó el Auto 180/1996, de 21 de febrero, fundamento jurídico 2.

17 Sentencia TC $101 / 2004$, de 2 de junio, fundamento jurídico 3.
}

De esta forma, el espacio público debe ser un lugar de convergencia del fenómeno religioso. Resulta, por ello, claro que las manifestaciones religiosas pueden y deben tener lugar en el ámbito social y público, presidido por la laicidad de los poderes públicos. En consecuencia, se debe rechazar cualquier interpretación que preconice una laicidad como ausencia de cualquier manifestación religiosa del ámbito público. Lo que no permite, simplemente, la neutralidad religiosa del Estado es la identificación o el respaldo gubernamental a determinadas creencias religiosas por encima o en detrimento de las demás.

El Tribunal Europeo de Derechos Humanos no ha mostrado preferencia por alguno de los distintos modelos de relación entre el Estado y las confesiones religiosas que se pueden identificar dentro de los cuarenta y siete estados que conforman el Consejo de Europa, donde existen estados confesionales - Reino Unido, Grecia, etc.junto a otros que han optado por modelo de separación estricta -Francia- pasando por aquellos que, como es el caso de España, Portugal e Italia, se han decantado por una separación entendida en términos de cooperación entre el Estado y las confesiones religiosas.

Como tuvo ocasión de indicar la Gran Sala en la Sentencia Leyla Sahín v. Turquía, se trata de una cuestión que entra dentro del margen de apreciación que corresponde a cada uno de ellos quienes, en consecuencia, pueden definir sus propios perfiles, atendiendo a consideraciones de tipo histórico, cultural, sociológico, etc., que resultarán legítimos en tanto no repercutan negativamente en el libre ejercicio de la religión de los ciudadanos y grupos religiosos 20 . De esta manera, quedan descartados modelos laicistas donde el Estado asume una posición de beligerancia frente al fenómeno religioso que se traduciría en obstáculos indebidos al libre ejercicio

\footnotetext{
18 Sentencia TC 46/2001, de 15 de febrero, fundamento jurídico 4.

19 Sentencia TC de 2 de junio de 2004, fundamento jurídico 3. 20 Sentencia TEDH Leyla Sahín, de 18 de marzo de 2011, ap. 109. Sentencia TEDH Izzetin Dogan de 26 de abril de 20016 , aps. 161-163.
} 
de la religión por parte de sus legítimos titulares. De la misma manera, excederían su margen de apreciación aquellos estados que instauraran un modelo de confesionalidad material que se tradujera en discriminaciones indebidas para aquellos que profesen una religión distinta de la del Estado.

\section{LA REALIDAD DE LOS ACUERDOS DE COOPERACIÓN}

Quizá el mayor exponente de la laicidad positiva en España lo constituyen los acuerdos de cooperación entre el Estado y las confesiones. A través de ellos se consigue adaptar el régimen jurídico general previsto en la Ley Orgánica de Libertad Religiosa a las características de cada una de ellas. Conviene recordar que la firma de Acuerdos está limitada a aquellas confesiones religiosas que, por su ámbito y número de creyentes, hayan alcanzado notorio arraigo en España. Conviene advertir, en este punto, que el reconocimiento del notorio arraigo por la Administración no atribuye a la confesión religiosa un derecho a la firma de acuerdos, ya que el Estado dispone de un cierto margen de discrecionalidad para valorar la oportunidad política de su firma con una confesión religiosa determinada.

En este sentido, desde posiciones minoritarias se ha llegado a defender la conveniencia de prescindir de estos acuerdos, por entender que responden a un paternalismo del poder público respecto a las confesiones religiosas que, en la actualidad, resulta superado debido, de un lado, a la consolidación del modelo constitucional y, de otro, a un cambio en las circunstancias que rodean a la realidad española, entre las que se destacan el multiculturalismo y la progresiva secularización de la sociedad (Fernández-Coronado, 2009). Según esta posición, lo que demanda la nueva realidad social es una cooperación entendida como un "simple canal de desarrollo de derechos fundamentales", de forma que cuando sea preciso armonizar los puntos de fricción entre el derecho estatal y el derecho confesional -referidos a contenidos imprescindibles para la plena realización de los derechos fundamentales de los fieles- lo más oportuno resultaría acudir a la legislación unilateral o a otros instrumentos que han empezado a tener entrada en nuestro Derecho, como la Fundación Pluralismo y Convivencia (Ciaurriz, 2008).

A mi juicio, los vigentes acuerdos han sido $-\mathrm{y}$ continúan siéndolo- instrumentos adecuados de desarrollo de la Ley Orgánica de libertad religiosa, por medio de los cuales, se ha intentado atender las particularidades de los distintos grupos confesionales, determinando lo particular $y$ específico que se puede reconocer a cada confesión (Viladrich; Ferrer, 2004).

Partiendo de esta premisa, las sospechas de una hipotética desigualdad entre confesiones quedan difuminadas al recordar que igualdad no es sinónimo de uniformidad. Así lo ha subrayado la doctrina científica en abundantes ocasiones, poniendo de relieve que una innovación normativa, por vía de acuerdo, al beneficiar a unas, no necesariamente va en detrimento de otras. Por el contrario, si por un acuerdo queda beneficiada una confesión o iglesia determinada, eso no quiere decir que las otras confesiones queden perjudicadas (Fornés, 2009).

A mayor abundamiento, cabe recordar la reiterada doctrina sentada por el Tribunal Constitucional en su sentencia $22 / 1981$, de 2 de junio, según la cual "la igualdad sólo es violada si la desigualdad está desprovista de una justificación objetiva y razonable, y la existencia de dicha justificación debe apreciarse en relación a la finalidad y efectos de la medida considerada, debiendo darse una relación razonable de proporcionalidad entre los medios empleados y la finalidad pretendida" 21.

Por su parte, el Tribunal Europeo de Derechos Humanos en la sentencia Savez Crkava v. Croacia $(2010)^{22}$ puso de manifiesto que la conclusión de acuerdos entre el Estado y una comunidad religiosa estableciendo un régimen jurídico particular para ella no contraviene el principio de igualdad y no discriminación religiosa, siempre y 
cuando responda a una justificación objetiva y razonable y no se impida la firma de acuerdos similares a otros grupos religiosos que puedan estar interesados. Dicho de otra manera, lo que impide la igualdad religiosa es que el Estado emplee la firma de acuerdos como un elemento de discriminación entre confesiones religiosas. Paralelamente, se debe tener en cuenta, siguiendo la doctrina de la Corte contenida en la sentencia Religionsgemeinschaft, que la firma de acuerdos con las confesiones religiosas en condiciones de igualdad se vincula también con el principio de laicidad, ya que el deber de neutralidad de las autoridades estatales en el ejercicio de sus competencias en la materia supone que todos los grupos tengan la posibilidad de disfrutar de la misma posición jurídica y que los requisitos establecidos a tales efectos sean aplicados de manera igualitaria. ${ }^{23}$

\section{CONCLUSIONES}

Hace algunos años se abrió en España un debate acerca de la modificación de la Ley Orgánica de Libertad Religiosa con el objetivo de hacer avanzar la laicidad. Se trataba de una justificación un tanto preocupante en tanto trasladaba la idea de que ésta debe condicionar el libre ejercicio de la religión, cuando debe ser justo a la inversa.

La promoción de la laicidad resulta un objetivo loable en un Estado de Derecho, por su apuntada repercusión sobre una mayor la libertad religiosa. Sin embargo, al tratarse de realidades distintas un derecho fundamental y un principio informador de la actuación del Estado en materia religiosadeben encontrar cauces de realización diferentes. La experiencia acumulada a lo largo de más de treinta años de vigencia del modelo de relaciones Estado-iglesias han puesto de manifiesto la necesidad de introducir algunas mejoras que posibiliten un ejercicio más pleno y eficaz de la libertad religiosa por parte de los ciudadanos y de las confesiones. Algunas ya se han implementado

23 Sentencia TEDH, de 30 de junio de 2008, ap. 92.

24 El reconocimiento del notorio arraigo de las confesiones religiosas está regulado en el Real Decreto 593/2015, de 3 de julio. como por ejemplo la sujeción al procedimiento administrativo del reconocimiento del notorio arraigo a las confesiones religiosas. ${ }^{24}$ Otras, en cambio, siguen pendientes. Entre ellas, se podría aludir a cuestiones de financiación de las confesiones religiosas, la precisión del estatuto jurídico de los ministros de culto o un mejor desarrollo del derecho a la asistencia religiosa. 25

Por todo ello podemos afirmar que el modelo actual se asemeja a un árbol que ha producido junto a frutos espléndidos también madera seca. Ante esto un determinado sector pedirá talar el árbol y plantar un nuevo modelo de relación, caracterizado por una concepción estricta de la separación. Otro reclamará dejarlo intacto. Frente a ambas posturas es posible un compromiso: podarlo, esto es, corregir algunas de sus imprecisiones, de suerte que se conserve el tronco y se posibilite el nacimiento de ramas nuevas que traigan, a su vez, mejores frutos.

\section{BIBLIOGRAFÍA}

Blanco, M. (1 999). La primera ley española de libertad religiosa: la génesis de la ley de 1967. Pamplona, España: Eunsa.

Cañamares, S. (2010), Ley Orgánica de Libertad Religiosa. Oportunidad y Fundamento de una Reforma. Ius Canonicum, Vol. 50.

Ciáurriz, M. J. (2008). La Fundación Pluralismo y Convivencia, en ÁLVAREZ, A. C., RODRÍGUEZ, M. (Coords.) Aspectos del régimen económico y patrimonial de las confesiones religiosas. Granada, España: Ed. Comares.

Ciáurriz, M. J. (1984). La libertad religiosa en el Derecho español. La Ley Orgánica de Libertad Religiosa. Madrid, España: Ed. Tecnos.

Cole durham, W. (2006). La importancia de la experiencia española en las relaciones IglesiaEstado para los países en transición, en AA.VV.

25 Sobre los aspectos susceptibles de mejora en la actual Ley Orgánica de Libertad Religiosa, me remito a mi trabajo Cañamares, S. (2010). También, Martínez, (2009). 
Estado y religión en la Constitución española y en la Constitución europea. Granada, España: Ed. Comares.

Fernández, A. (2009). Sentido de la cooperación del estado laico en una sociedad multirreligiosa. Revista General de Derecho Canónico y Eclesiástico del Estado, $N^{\circ} 19$.

Fornés, J. (2009). Consideraciones sobre la Ley Orgánica de Libertad Religiosa de 1980, con sus perspectivas de futuro. Revista General de Derecho Canónico y Eclesiástico del Estado, N 19.

García, R. (2013). La Ley de Libertad Religiosa portuguesa, Derecho y Religión. $\mathrm{N}^{\circ} 8$.

García, D. (1999). El sistema de acuerdos con las confesiones minoritarias en España e Italia. Madrid, España: Ed. CEPC.

González, M. (2013). Las leyes de libertad religiosa española y portuguesa y su influencia en las leyes y en algunos proyectos de ley de libertad religiosa latinoamericanos. Revista General de Derecho Canónico y de Derecho Eclesiástico del Estado- $\mathrm{N}^{\circ} 32$.

Llamazares, D. (2002). Portugal: Ley de Libertad Religiosa, 2001. Laicidad y Libertades. Escritos jurídicos. $\mathrm{N}^{\circ} 2$.

Llamazares, D. (1999). A vueltas con la laicidad. Estudios jurídicos en homenaje al profesor Vidal Guitarte. Castellón, España: Diputación de Castelló. Volumen 2.

López, M.; Goti J. (1996). Valores religiosos y Constitución en una sociedad secularizada. Secularización y laicidad en la experiencia democrática moderna San Sebastián, España: Librería Carmelo.

Mantecón, J. (2015). Breve nota sobre el nuevo Real Decreto sobre el Registro de Entidades Religiosas. Ius Canonicum.

Martínez, J. (2009). La Ley Orgánica de Libertad Religiosa, veintiocho años después, en Revista General de Derecho Canónico y Eclesiástico del Estado, $\mathrm{N}^{\circ} 19$.

Martínez, J. (2003). Los límites a la libertad de religión y de creencia en el Convenio Europeo de Derechos Humanos. Revista General de Derecho Canónico y de Derecho Eclesiástico del Estado, $\mathrm{N}^{\circ}$ 2.

Navarro, R. (2003). Los Estados frente a la Iglesia. Estado y Religión, Ed. Ariel.

Ollero, A. (2005). España ¿un Estado laico? Madrid, España: Civitas.

Palomino, R. (2014). Neutralidad del Estado y espacio público, Navarra, España: Ed. Aranzadi.

Roca, M. (2005). Teoría y práctica del principio de laicidad del Estado. Acerca de su contenido y función jurídica. Persona y Derecho.

Suárez, G. (2006). La Laicidad en la Constitución española. Estado y religión en la Constitución Española y en la Constitución Europea. Granada, España: Ed. Comares.

Viladrich, P. J.; Ferrer, J. (2004). Los principios informadores del Derecho Eclesiástico español. FERRER, J. (Coord.), Derecho Eclesiástico del Estado español, Pamplona, España: Ed. Eunsa. 